\title{
Pesquisas atuais sobre a construção do conceito de número: para além de Piaget?
}

\section{Current researches about the construction of the number concept: beyond Piaget?}

\author{
Clélia Maria Ignatius Nogueira ${ }^{1}$
}

\begin{abstract}
RESUMO
As atuais pesquisas acerca da construção do número vêm resgatando o papel desempenhado pelas atividades numéricas (em particular, a contagem) na construção do número. Para a maioria dos autores dessas pesquisas e outros estudiosos do tema, os resultados mais recentes, quando não contrariam, ultrapassam, do ponto de vista teórico, o estágio alcançado pelas pesquisas do Centro Internacional de Epistemologia Genética. Neste trabalho discutimos o papel da contagem no desenvolvimento do número segundo a Epistemologia Genética. Buscando destacar a atualidade da teoria piagetiana, comentamos algumas das recentes pesquisas e propostas metodológicas sobre a construção do conceito de número que se fundamentam quase que exclusivamente na contagem, procurando verificar se os resultados encontrados ou as sugestões apresentadas pelos pesquisadores estariam, do ponto de vista teórico, "além de Piaget".

Palavras-chave: contagem; construção do número; epistemologia genética.
\end{abstract}

\begin{abstract}
Current researches about number construction are recovering the role played by numerical activities (specially counting) in number construction. For most of the authors and other scholars, recent results regarding that subject, if not denying the stage of knowledge reached by the International Center of Genetic Epistemology, they surpass it from the theoretical point of view. In this study, the role of counting in number development according to the Genetic Epistemology is discussed. The contemporary value of the Piagetian theory is pointed out by contrasting it to recent researches results
\end{abstract}

1 Doutora - Universidade Estadual de Maringá - UEM, Maringá, Paraná, Brasil. E-mail: cminogueira@uem.br 
and methodological proposals about the construction of the number concept which are based, almost exclusively, on counting, in order to question if their results or their suggestions would be, theoretically, "beyond Piaget". Keywords: counting; number construction; genetic epistemology.

\section{Introdução}

Uma das noções fundamentais da Matemática, a ideia de número, foi construída e aperfeiçoada ao longo de muitos séculos. Surgiu da necessidade humana de conhecer o mundo e nele sobreviver. Foi dessa necessidade e utilizando objetos para a contagem que a humanidade começou a construir o conceito de número.

Mas, e a criança, como ela adquire esse conceito?

De acordo com Piaget e Szeminska (1981), a criança constrói progressiva e interiormente a capacidade de contar com sucesso os objetos e essa capacidade só está consolidada quando ela consegue coordenar várias ações sobre os objetos (classificação, seriação, correspondência biunívoca, entre outras), a fim de quantificá-los. Conhecer "de cor"” a sequência de palavras utilizadas na contagem não significa já ter construído a estrutura de número.

Duas afirmações de Piaget têm sido evocadas para justificar a ênfase nas atividades lógicas em detrimento de atividades numéricas na Educação Infantil. Uma, é a de que "não é suficiente à criança saber contar verbalmente para que esteja de posse do número", e a outra, a de que a sucessão dos números se constitui "em síntese operatória da classificação e da seriação". Ambas as afirmações constam do livro $A$ gênese do número na criança e foram escritas pelo próprio pesquisador; a primeira, no prefácio da terceira edição (PIAGET; SZEMINSKA, 1981, p. 15) e a segunda no prefácio da primeira edição do referido livro (PIAGET; SZEMINSKA, 1981, p. 12).

Um exemplo do que foi afirmado no parágrafo anterior pode ser comprovado, por exemplo, pelo programa de 1970 do Curso Preparatório (o equivalente francês da Educação Infantil brasileira), que apresenta, na descrição dos conteúdos, explicitamente os tópicos "atividades de classificação e de seriação":

É através das diversas manipulações de objetos que as crianças elaboram pouco a pouco a noção de número natural. É necessário compreender bem 
que o número natural não é um objeto, nem uma propriedade vinculada a objetos, mas sim uma propriedade vinculada a conjuntos.

[...] A noção de número natural como propriedade de um conjunto aparecerá na medida em que se poderá estabelecer correspondência termo a termo entre conjuntos...

[...] O emprego sistemático da correspondência termo a termo permite classificar os conjuntos e atribuir a cada classe um número: assim, a classe de todos os conjuntos que têm objetos em quantidade igual aos dedos da mão define o numeral "cinco".

[...] Convém frisar a importância, para a elaboração da noção de número natural, das atividades de classificação, de seriação, de correlação termo a termo realizadas na escola maternal ${ }^{2}$ (ERMEL, 1991, p. 4).

Como as crianças nascem em um mundo, no qual os números são quase inerentes aos objetos, é legítimo indagar qual a importância tanto do processo de contagem para a construção do conceito de número como a do conhecimento de número que a criança possui antes de entrar na escola.

As atuais pesquisas acerca da construção do número vêm resgatando o papel desempenhado pelas atividades numéricas (em particular, a contagem) na construção do número. As novas orientações para o trabalho com números na Educação Infantil não apresentam mais, pelo menos de forma explícita, como "conteúdos a serem ensinados" as atividades lógicas consideradas "prénuméricas" como classificação e seriação e, muito menos, desestimulam o uso da contagem como acontecia em um passado não muito remoto.

O reconhecimento da importância da contagem na construção do número pela criança estabelecida pela maioria dessas pesquisas contraria ou ultrapassa, do ponto de vista teórico, os resultados obtidos pelas pesquisas do Centro Internacional de Epistemologia Genética sobre a construção do número?

Outro ponto abordado pelas recentes pesquisas se refere às capacidades numéricas precoces das crianças ou, dito de outra forma, ao momento que as crianças adquirem o conceito de número. A comprovação da existência de atividades numéricas eficientes como contagem e quantificação de coleções antes dos seis ou sete anos ${ }^{3}$ contraria ou ultrapassa, do ponto de vista teórico, os resultados obtidos pelas pesquisas do Centro Internacional de Epistemologia Genética sobre a construção do número?

Neste artigo, discutimos o papel da contagem no desenvolvimento do

2 Tradução livre e de responsabilidade da autora.

3 Período estabelecido pelas pesquisas piagetianas para que a síntese original da classificação e da seriação se complete. 
número segundo a Epistemologia Genética e comentamos algumas das recentes pesquisas, procurando verificar se os resultados encontrados acerca da contagem e das capacidades numéricas precoces das crianças estariam, do ponto de vista teórico, "além de Piaget".

\section{A contagem}

Ao analisarmos as ações que a criança precisa desenvolver para contar objetos fica evidente que o número resulta da síntese original da classificação e da seriação, conforme sistematizado por Rangel (1992):

- Juntar os objetos que serão contados, separados dos que não serão contados (classificação);

- Ordenar os objetos para que todos sejam contados e somente uma vez (seriação);

- Ordenar os nomes aprendidos para a enumeração dos objetos, utilizando-os na sucessão convencional, não esquecendo nomes e nem empregando o mesmo nome mais de uma vez;

- Estabelecer a correspondência biunívoca e recíproca nome-objeto; e finalmente;

- Entender que a quantidade total de elementos de uma coleção pode ser expressa por um único nome.

Assim, contar é estabelecer a correspondência biunívoca termo a termo, entre quatro tipos de elementos: os objetos, os gestos, o olhar, as palavrasnúmero. De maneira geral, é a partir dos 6-7 anos que a contagem torna-se confiável e, portanto, passa a ser a maneira mais utilizada pelas crianças para a determinação de quantidades.

Quando as quantidades a serem comparadas são pequenas, a percepção visual ou a correspondência um a um sem contagem são recursos úteis. Porém, se as quantidades são maiores, suas utilidades tornam-se discutíveis e aí, um novo instrumento, a contagem, introduzida pela família, na interação com o meio e enfatizada pela escola, torna-se o utensílio privilegiado para a comparação e quantificação de coleções. 
Esse recurso, todavia, não é aceito de imediato pelas crianças e nem pode ser transmitido socialmente, para se tornar uma ferramenta confiável. Existe uma fase de transição, distinguida, segundo Piaget (PIAGET; SZEMINSKA, 1981, p. 17), por Gréco, denominada de "conservação da quotidade", na qual a criança consegue contar corretamente, mas confia mais na percepção visual do que no resultado da contagem para comparar duas quantidades.

De acordo com Chalon-Blanc (2008), Gelman e Gallistel, em pesquisa realizada em 1978, concluíram que a atividade de contagem é dirigida por cinco princípios: o princípio da ordem estável, segundo o qual as palavras-números devem constituir uma sequência estável; o princípio da correspondência termo a termo, segundo o qual, a cada elemento contado corresponde a uma e só uma palavra-número; o princípio cardinal, segundo o qual a última palavra-número utilizada numa sequência de contagem representa o número de elementos do conjunto contado; o princípio da abstração, segundo o qual o conjunto em que incide a contagem pode ser constituído por elementos heterogêneos, todos eles tomados como unidades e o princípio da não pertinência da ordem, segundo o qual a contagem dos elementos pode ser feita em qualquer ordem, desde que os outros princípios sejam respeitados. Os três primeiros princípios definem o procedimento de contagem, o quarto determina o tipo de conjunto em que a contagem pode incidir e o quinto permite distinguir a contagem da simples etiquetagem.

Gelman e Gallistel (apud CHALON-BLANC, 2008) afirmam que a criança mesmo muito pequena possuiria um conhecimento implícito desses cinco princípios, que consistiriam competências pré-formadas, que orientariam seu desempenho. Fica difícil não observar a forte tendência inatista desses argumentos e de que não há, nesses resultados, nenhuma discussão acerca da participação da contagem no desenvolvimento do conceito de número.

A americana Karen Fuson (1991) investigou, com detalhes, a evolução entre contagem e cardinalidade, em crianças de idade variando entre dois e oito anos e seus resultados deixaram evidente a importância dos procedimentos empíricos para a constituição da quantificação e da contagem para a construção do número. Para a pesquisadora, muito antes de construir o número de um ponto de vista lógico, a criança encontra as palavras-número em uma variedade de situações entre as quais vai estabelecer ligações e identificou sete situações: cardinalidade; de medida; ordinalidade; contagem (no sentido de etiqueta numa correspondência biunívoca); sequencial (recitar apenas as palavras-número); simbólica (apenas a leitura de um numeral) e como código (canal de TV).

Fuson (1991) estabeleceu que a contagem é um instrumento cultural utilizado pela criança para construir os conceitos de número cardinal, ordinal e de número-medida, quando se trata de coleções de média dimensão. 
Fuson, Richards e Briars (1982) descreveram com precisão a evolução da cadeia verbal: $o$ "rosário", quando as palavras-número não são diferenciadas no seio da sequência; $a$ "lista indivisivel", quando as palavras-número são diferenciadas, mas a contagem só pode começar no princípio da lista; $a$ "cadeia divisivel", quando a contagem pode ser iniciada em qualquer ponto e a sequência de palavras-número começa a ser recitada ao contrário e $a$ "cadeia enumerável", quando as palavras-número da sequência adquirem significado cardinal, o que permite à criança contar $\mathrm{n}$ elementos (a mais ou a menos) a partir de qualquer número.

Ao estabelecer o papel desempenhado pela contagem na construção do número, Fuson (1991) também se manifestou explicitamente em relação às pesquisas piagetianas e, para ela, Piaget subestimou tanto o papel da contagem na construção do número, quanto o das estratégias empíricas de emparelhamento (correspondência) para a quantificação.

Steffe (1991), após ter trabalhado durante dez anos tentando compreender como a teoria piagetiana dos estágios poderia ser utilizada no ensino da Matemática, sentiu necessidade de formular um modelo da construção do número, compatível com o de Piaget, levando em conta, porém, a experiência infantil. Seus estudos permitiram isolar cinco estádios de aprendizagem na construção da sequência dos números: 1) esquema de contagem perceptiva; 2) esquema de contagem figurativa; 3 ) a sequência inicial dos números; 4) a sequência tacitamente encaixada dos números e, 5) a sequência explicitamente encaixada dos números. Para ela, Piaget não considerou os suportes da experiência infantil na qual, em decorrência da interação social, a contagem se faz presente.

Lifschitz e Langford, de acordo com Chalon-Blanc (2008), em pesquisa de 1977, concluíram que a melhor forma de se ensinar crianças pequenas a conservarem a quantidade consiste em treinar a adição e a subtração. Ressaltaram também que a prática sistemática da enumeração reforça a duração e a estabilidade das conservações.

Sophian (1991) pesquisou a relação entre a cardinalidade e a contagem em crianças não escolarizadas, com a idade variando de três a sete anos. Encontrou resultados que revelam uma compreensão precoce tanto da contagem quanto de algumas operações matemáticas elementares. Baseada nesses resultados, a pesquisadora recomenda a inclusão de atividades que privilegiem a contagem e mesmo operações aritméticas a partir das primeiras aprendizagens, desde que integradas a uma pedagogia contextualizada.

Segundo Sophian (1991), nos resultados piagetianos a contagem "desempenha um papel secundário no desenvolvimento das conceitualizacões numéricas" enquanto que os trabalhos recentes a consideram, tanto "como um indicador da riqueza dos conhecimentos matemáticos desde a pequena infância", quanto 
"um fator potencialmente importante do desenvolvimento das conceitualizações relativas ao número" (SOPHIAN, apud BIDEAUD; MELJAC; FISHER, 1991, p. 35).

Brissiaud (1989) estabelece uma "oposição" entre os resultados piagetianos e a comprovação, em diversas pesquisas, tanto do papel efetivo desempenhado pela contagem na construção do número, quanto da presença do número no pensamento infantil, antes do acabamento deste último (em torno dos seis ou sete anos, como síntese das classes e das séries). Segundo este estudioso francês, Piaget menospreza a contagem ao considerar que o fator verbal desempenha apenas um papel pequeno no progresso da construção do número. Para Brissiaud (1989), as crianças conhecem o número antes da contagem, ao estabelecer, da mesma forma que o fizeram nossos ancestrais, uma correspondência biunívoca entre uma coleção de objetos e a mesma quantidade de dedos, que ele denomina por "coleção-testemunho" de dedos (BRISSIAUD, 1989, p. 25).

De acordo com Chalon-Blanc (2008), um resultado importante foi obtido por Bideaud e Jablonka ao investigaram as contribuições da enumeração no desenvolvimento da noção de número em crianças com 4 anos de idade. A pesquisa consistia em investigar a conservação de quantidade. Era solicitado às crianças que realizassem a correspondência termo a termo entre duas coleções. Após essa realização, o experimentador transformava uma das coleções ou ambas e interrogava sobre a igualdade numérica, sugerindo que contém e mostrando que o número das duas coleções é idêntico. Os pesquisadores concluíram que, após auxiliadas seguidamente, durante um mês depois da aplicação do pré-teste, as crianças realizaram a correspondência termo a termo entre duas coleções e afirmavam a conservação, no pós-teste; porém, esses progressos foram de pouca duração (não conservavam, mesmo com o auxílio da contagem, no segundo pós-teste um mês mais tarde) e foram pouco generalizáveis.

\section{Por que a enumeração não é considerada nas investigações reali- zadas por Piaget e Szeminska sobre a gênese do número na crian- ça?}

Para os pesquisadores, o fundamental em uma investigação que busca as origens do número é identificar em que momento as crianças passam de raciocínios fundamentados apenas nas qualidades dos objetos para raciocínios sustentados nas quantidades que estabelecem. Assim, a contagem não foi considerada porque essa atividade não lhes pareceu essencial para compreender a 
construção do conceito do número.

Se por concentrarem seus estudos no desenvolvimento intelectual das crianças (pressupondo operações), Piaget e Szeminska (1981) não desenvolveram maiores análises sobre a contagem (pressupondo interação social) das crianças, isto não é, contudo, suficiente para se concluir que os autores não a considerassem importante.

Ao contrário, buscando exatamente complementar os estudos de Piaget e Szeminska, e sob a supervisão do primeiro, conforme já citado anteriormente, Pierre Gréco pesquisou, no início da década de sessenta, o papel da contagem e da correspondência termo a termo no desenvolvimento do número. Os resultados de Gréco foram publicados inicialmente no artigo Quantidade e Quotidade: novas pesquisas sobre a correspondência termo a termo e a conservação dos conjuntos, e, em versão mais completa, em conjunto com Albert Morf, no volume XIII dos Études d'épistémologie génétique, intitulado Structures Numériques Élémentaires, em 1962.

Gréco e Morf (1962) investigaram se o conhecimento da enumeração influencia ou não a conservação de uma quantidade discreta e estabeleceu a precocidade da conservação da quotidade (resultado da enumeração), o que o levou a atribuir um importante papel tanto à contagem, quanto à correspondência termo a termo na construção do número.

Nessa pesquisa, que pode ser considerada o marco inicial dos estudos posteriores acerca da contribuição da contagem na construção do número, Gréco e Morf (1962) concluíram pela existência de uma fase de construção do número entre a II (da correspondência qualitativa - sem conservação) e a III (da correspondência operatória) estabelecidas nos estudos de Piaget e Szeminska (1981). A fase estabelecida é a da conservação da quotidade sem conservação da quantidade e é reconhecida por Piaget, conforme consta do prefácio da terceira edição francesa do livro $A$ gênese do número na criança, prefácio este datado de maio de 1964:

[...] as fases sucessivas são então as seguintes: 1) a criança constrói uma fileira do mesmo comprimento, mas sem correspondência termo a termo; 2) ela consegue uma correspondência ótica exata, mas se se espaça um pouco os elementos de uma das fileiras, a criança acredita que a fileira mais comprida adquire, por este fato, um número superior ( $8 \mathrm{em}$ vez de 7 , etc.); 3) na mesma situação, a criança pensa que o número se conserva mas que a quantidade aumenta (conservação da quotidade, mas não ainda da quantidade), com o nome numérico, pois, não sendo, ainda, mais que um meio de individualizar os elementos, mas sem que a quantidade total seja concebida como igual à soma das partes; 4) na mesma situação, há, daí 
por diante, conservação tanto da quantidade como da quotidade (PIAGET, apud PIAGET; SZEMINSKA, 1981, p. 19).

O fato de Piaget e Szeminska (1981) não terem considerado a contagem em sua investigação produziu questionamentos à teoria piagetiana, com críticas como, por exemplo, a de que os mesmos autores relegaram a contagem a um segundo plano, por desprezarem os conhecimentos decorrentes da interação social.

Sendo a contagem um conhecimento com características sociais, um "componente verbal" do número, existe um algo mais embutido na crítica ao alegado desprezo dispensado pelos pesquisadores ao papel da contagem na construção do número. $\mathrm{O}$ que parece é que se pretende retomar, em novo cenário, a antiga crítica endereçada à Epistemologia Genética sobre o suposto descuido com o fator social na construção do conhecimento.

Com relação ao fator social, Nogueira (2007, p. 236) alerta que "não se pode, também, desprezar importantes constatações que estão implícitas no livro em questão e que se referem à interação social, como no caso da análise das composições aditivas...". A esse respeito, Piaget e Szeminska (1981, p. 231) concluem que "o fato de designar as classes totais e parciais por nomes especiais ajuda a diferenciá-las e a hierarquizá-las". Isto significa que as crianças apresentam maior facilidade para incluir hierarquicamente em situações em que as classes em jogo podiam ser designadas e delimitadas por uma palavra ou sistemas de palavras, demonstrando que o conhecimento social colabora com as construções lógicas.

Para poder contar, a criança inicialmente deve ser capaz de estabelecer uma "unidade". Como "unidade" é uma propriedade que é acrescentada aos objetos, quando se igualizam as diferenças (ao se separar, por exemplo, o que será contado do que não será contado), elas são "constituídas" graças às capacidades de abstração, antes de serem nomeadas, o mesmo acontecendo com a correspondência, as classes e a ordenação, enfim, todo sistema é manipulado antes de ser efetivamente nomeado. Era este sistema que Piaget e Szeminska (1981) procuravam: eles buscavam indícios mais confiáveis de uma dedução que garantisse que a quantidade permanecia em potência independente de todas as suas aparências.

Por outro lado, ainda se considerando a abstração, as tarefas de contagem, ou as que favorecem a construção do conceito de número, são facilitadas pela linguagem. 
[... ] a linguagem, ao designar as relações que já existiam entre as unidades traçadas, estabiliza o sistema e dá-lhe, simultaneamente, uma possibilidade muito rápida de evocação e de evolução (CHALON-BLANC, 2005, p. 33).

Entendemos que Piaget nunca afirmou que a função simbólica não desempenhava nenhum papel na construção do número. Em nossa análise do livro $A$ gênese do número na criança, constatamos que os autores pretendiam demonstrar a anterioridade do sistema dos números em relação à sua designação e, particularmente, sobre sua designação coletiva, em termos de signos.

Piaget e Szeminska (1981) demonstraram que as crianças conservam quantidades discretas e, portanto, manipulam verdadeiros números, sem saberem nomeá-los. Gréco e Morf (1962) demonstraram que as crianças são capazes de manipular as palavras-número sem as compreender.

Essas diversas constatações evidenciam que a enumeração não é um fator decisivo na construção do conceito de número, sendo, porém, indispensável à sua evolução. De acordo com Piaget e Szeminska (1981, p. 97), "no momento em que a correspondência se torna quantificante e dá assim nascimento a começos de equivalência, a numeração falada pode acelerar o processo de evolução". Além disso, o poder evocador da numeração permite acesso a números grandes e às operações.

\section{A enumeração no ensino do número e a teoria piagetiana}

Algumas das pesquisas acerca da influência da enumeração na construção do conceito de número anteriormente citadas indicam que certos aspectos do número são seguramente culturais e, assim, as crianças constroem as pré-noções cardinais (responder à questão quanto) e ordinais (mostrar o n-ésimo elemento) muito antes de terem construído os elementos lógicos do número.

É fato também que as transmissões culturais (palavras-números, canções, enumeração ou contagem, aprendizagem reforçada) são insuficientes para reconhecer um número do qual não se utiliza sistematicamente, porém, em contrapartida, são necessárias para construir a ferramenta matemática a uma velocidade normal.

Outro aspecto importante a ser considerado é que para uma criança do século XXI a aquisição do conceito de número obedece a uma ordem inversa da ordem em que o conceito foi construído pela humanidade, afinal, elas convivem 
socialmente com as palavras-número antes de construírem a sequência numérica.

Esse "conhecimento" social que as crianças atualmente possuem da sequência das palavras-número, dos numerais, permite que compreendamos melhor a insistência acerca da importância da contagem no desenvolvimento do conceito de número.

$\mathrm{Na}$ construção do conceito de número, ou seja, a capacidade de abstrair uma mesma quantidade a partir de objetos diferentes; de configurações espaciais diferentes, a criança passa por etapas que são parcialmente semelhantes às etapas dos "inventores" do número. Os obstáculos a vencer e as soluções a encontrar são sempre os mesmos. Sem conservação do todo não há quantidade e isso é verdadeiro em 2009 como o era em 3500 a.C. Todavia, de acordo com Chalon-Blanc (2008), esse processo exigirá de cada criança de 6 a 7 anos e não milênios, como necessitou a humanidade, pois a criança se encontra, desde o seu nascimento, mergulhada em diferentes contextos numéricos.

As variações do meio podem, eventualmente, modificar a velocidade das aquisições, mas não a natureza dos obstáculos a vencer e, assim, a construção da quantidade conserva um máximo de coerência com suas origens, embora esteja imersa em um conjunto infinitamente mais vasto do que o conjunto de origem

ao qual pertencia. É essa incrível redução do tempo que evidencia a importância da transmissão de maneira implícita, nas atividades cotidianas, ou de maneira explícita, no contexto escolar, de conhecimentos processuais ou declarativos, distintos daqueles que a criança constrói individualmente. No caso do número, a enumeração é o principal desses conhecimentos.

\section{As capacidades numéricas precoces}

Chalon-Blanc (2008) analisando algumas investigações realizadas nos Estados Unidos acerca das capacidades numéricas precoces das crianças, como as de Starkey e Cooper; de Karmiloff-Smith e de Wynn, entende que nos resultados americanos prevalece a ideia do inatismo, pois defendem que a criança conta com princípios precoces prévios.

Investigações realizadas por Starkey e Cooper (apud CHALON-BLANC, 2008) comprovam que bebês, por volta dos 6 meses de idade, podem distinguir entre conjuntos de um, dois ou três elementos, bem como entre conjuntos de três e quatro elementos.

Os resultados de Karmiloff-Smith (apud CHALON-BLANC, 2008) indicam que crianças com um ano de idade podem ordenar conjuntos com diferentes 
quantidades de elementos, podendo dar conta de pequenas mudanças numéricas no conjunto que está observando e ignorar outros dados perceptivelmente interessantes como cor e forma. Seria um sentido numérico intuitivo, muito semelhante ao senso numérico do homem primitivo.

Ainda segundo Chalon-Blanc (2008), Wynn investigou, em 1992, se as operações com números pequenos são inatas e, utilizando a técnica da fixação visual, procurou saber se bebês entre quatro e cinco meses realizam sem dificuldade a adição $1+1=2$ e a subtração $2-1=1$. Seus resultados foram positivos. Porém, é importante destacar que o que Wynn considera como adição e subtração não possui o caráter das operações reversíveis de Piaget e Szeminska (1981); seus resultados estariam, a nosso ver, dentro da teoria piagetiana, ligados à questão do objeto permanente.

De maneira geral, as pesquisas que buscam identificar as capacidades numéricas precoces procuram estabelecer a "existência" do número antes da síntese entre a classificação e a seriação.

A comprovação das capacidades numéricas precoces das crianças contrariam os resultados piagetianos? Para responder a essa questão é necessário compreender a investigação realizada por Piaget e Szeminska (1991), na perspectiva da Epistemologia Genética.

Por que investigar a gênese do número?

Antes dos estudos com Szeminska que constituíram o livro $A$ gênese do número na criança, Jean Piaget já havia analisado as fontes práticas e sensóriomotoras do desenvolvimento da criança e publicado seus resultados em duas obras clássicas: O nascimento da inteligência na criança (1987) e A construção do real na criança (1996). Também já havia investigado os aspectos verbais e conceituais do pensamento infantil que resultaram em A formação do símbolo na criança (1990). Para Piaget ${ }^{4}$, era necessário "ultrapassar essas duas etapas preliminares e atingir os mecanismos formadores da própria razão", para compreender como os esquemas sensório-motores se organizavam no plano do pensamento em sistemas operatórios, o que, para ele, só seria possível mediante o estudo da gênese do número (PIAGET; SZEMINSKA, 1981, p. 18).

Por que não investigar as capacidades numéricas precoces das crianças?

Piaget e Szeminska (1981) estabeleceram que os sujeitos de sua investigação deveriam ser capazes de realizar tarefas inerentes às provas cognitivas programadas, limitando-os, então, ao período intuitivo ou pré-operatório. Assim, os sujeitos da pesquisa foram restritos a crianças do período intuitivo, não porque não existissem indicativos da presença do número em crianças mais jovens, mas, porque, toda análise metodológica necessita fixar "começos".

4 Prefácio da primeira edição do livro $A$ gênese do número na criança. 
Como foram estabelecidas as provas aplicadas durante a investigação?

Piaget e Szeminska (1981) se fixaram nas principais "qualidades" ou "necessidades" do número para existir, a conservação de quantidades (condição de todo e qualquer conhecimento); a correspondência termo a termo (essencial para a contagem); a determinação da cardinalidade e do princípio ordinal (aspectos indissociáveis do número). Em todas elas, segundo a análise que realizamos, os autores buscam confirmar a hipótese, não colocada explicitamente, de que o número é a síntese original da classificação e da seriação ${ }^{5}$.

Por que essa hipótese implícita?

Trazemos a posição de que, para responder esta pergunta, entra em cena o forte apelo epistemológico das soluções matemáticas insatisfatórias para a questão "o que é número?", particularmente, o longo e debate entre as correntes de pensamento matemático, a do logicismo e a do intuicionismo, com os logicistas, representados pelo filósofo e matemático inglês Bertrand Russell e os intuicionistas pelo cientista e matemático francês Henri Poincaré.

Aliam-se a essa questão as convicções de Piaget de que o conhecimento não está nem no sujeito (apriorismo, implícito no logicismo) e nem no objeto (empirismo, pano de fundo do intuicionismo), mas na interação entre ambos, uma interação particular, que acontece internamente ao sujeito. Pode-se inferir, assim, que Piaget procurava uma solução intermediária, um tertium, entre Russell e Poincaré6.

Temos claro que, na perspectiva piagetiana, o número tem por fonte a lógica, o que contempla o logicismo; porém, não deriva de nenhuma operação em particular. O número é construído das relações simétricas quando os sujeitos agrupam objetos por suas semelhanças, das relações assimétricas quando estabelecem as diferenças ordenadas, em uma síntese original e contínua dessas estruturas ao agruparem os objetos, ao mesmo tempo, como equivalentes e distintos, o que é conciliatório com a irredutibilidade de Poincaré.

Nas provas do livro A gênese do número na criança, as crianças refletem, estabelecem a correspondência termo a termo (qualquer e não qualitativa) $\mathbf{e}$ simultaneamente classificam e colocam em série e, é preciso destacar, não são impedidas de contar. Ao contrário, esta conduta é analisada nas provas envolvendo "trocas um contra um com numeração falada" e o resultado dessa análise é que "este fator verbal não desempenha qualquer papel no próprio progresso da correspondência e da equivalência” (PIAGET; SZEMINSKA, 1981, p. 97).

5 A hipótese explicitada pelos autores, no prefácio da edição de 1941, é a de que a construção do número seria correlata ao desenvolvimento da lógica.

6 Uma discussão completa acerca da hipótese de Piaget de que o número é síntese original entre a classificação e a seriação é feita em Nogueira (2006). 
Dito de maneira formal, para atingirem o status de estruturas operatórias, os três, número, classificação e seriação, desenvolve-se solidariamente, num processo de interdependência.

\section{Considerações finais}

Em relação às capacidades numéricas precoces da criança, o próprio fato, da elaboração da síntese original entre a classificação e a seriação não se dar de forma linear, mas, sim, sincrônica e solidariamente, já indica a presença de números primitivos (quantificadores), virtuais ou reais, a partir dos níveis mais elementares, o que já é relatado no livro $O$ nascimento da inteligência na criança (1987).

No que se refere à contagem, fundamentando-nos apenas na teoria piagetiana, pudemos considerar que ela, contagem, desempenha um papel importante na construção do conceito do número e, assim, tanto as atividades lógicas como as numéricas devem ser abordadas e exploradas no espaço escolar.

Afinal, embora as dificuldades e os obstáculos da construção do número, do sistema de numeração decimal e da escrita numérica possam ser, parecem, os mesmos para a criança e para a humanidade, existem recursos fornecidos pelo meio para que o processo seja incrivelmente acelerado e a contagem é o principal deles!

Teoricamente, uma conclusão possível, a partir das referências escolhidas para ilustrar os atuais "caminhos do número", é que o trabalho de Piaget e Szeminska (1981) continua na base destes estudos, quer estes pretendam confirmálos, complementá-los ou colocá-los em cheque. Isto demonstra bem, segundo os termos de Rémy Droz, "l'incroyable fécondidité heuristique" (a incrível fecundidade heurística), do trabalho de Piaget e Szemiska (DROZ, 1991, p. 286).

No que é atinente às questões didático-metodológicas, é fato que muitas outras variáveis estão envolvidas numa ação pedagógica de qualidade. Porém, nenhuma merece mais atenção do que o trabalho do professor, pois a compreensão que o professor possui da matemática é um fator decisivo para o sucesso do aluno.

Para Nogueira (2007), é muito importante que o professor conheça as fases da construção do número, especialmente a noção de quotidade, pois, levando a criança a contar coisas, favorece a elaboração do aspecto serial da numeração. Além disso, ao contar elementos, a criança aponta e diz a palavra-número, constituindo formas de equivalências numéricas e estabelecendo correspondência biunívoca. 
Assim, compreendendo o contexto no qual o professor da Educação Básica está inserido, suas necessidades, aspirações e condições; considerando o momento atual, com uma mudança substancial no ensino fundamental, representada pela ampliação de mais um ano, entendemos ser de fundamental importância que o professor enriqueça seu repertório teórico para subsidiar, de maneira consistente, seu fazer pedagógico.

\section{REFERÊNCIAS}

BRISSIAUD, R. Como as crianças aprendem a calcular. Tradução de: RANGEL, A. Lisboa: Instituto Piaget, 1989.

CHALON-BLANC, A. Inventar, contar e classificar: de Piaget aos debates actuais. Tradução de: FIGUEIREDO, L. Lisboa: Instituto Piaget, 2008.

DROZ, R. Les multiples racines des nombres naturels et leurs multiples interprétations. In: BIDEAUD, J.; MELJAC, C.; FISHER, J. P. Les Chemins du nombre. Lille: Presses Universitaires, 1991. p. 285-302.

ERMEL, Institut Nacional de Recherche Pédagogique. Aprendissages numériques et résolution des problèmes. Cours préparatoire. Paris: Hatier, 1991.

FUSON, K. Relations entre comptage et cardinalitè chez lês enfants de 2 à 8 ans. In: BIDEAU, J.; MELJAC, C.; FISHER, J. P. Les chemins du nombre. Lille: Presses Universitaires de Lille, 1991. p. 159-179.

FUSON, K.; RICHARDS, J.; BRIARS, D. J. The acquisition and elaboration of the number word sequence. In: BRAINERD, C. (Org.). Progress in cognitive development: Children's logical and mathematical cognition. New York: Springer-Verlag, 1982. v. 1. p. 33-92.

GRÉCO, P.; MORF, A. Structures numériques élémentaires. Études d'Epistémologie Génétique. Paris:Presses Universitaires de France, 1962. v. XIII.

NOGUEIRA, C. M. I. A definição de número: uma hipótese sobre a hipótese de Piaget. Revista Brasileira de Estudos Pedagógicos, v. 87, n. 216, p. 135-144, 2006.

. Classificação, seriação e contagem no ensino do número: um estudo de Epistemologia Genética. Marília: Oficina Universitária Unesp, 2007.

PIAGET, J. O nascimento da inteligência na criança. 4. ed. Tradução de: CABRAL, 
Á. Rio de Janeiro: Guanabara, 1987.

. A formação do símbolo na criança. 3. ed. Tradução de: CABRAL, Á.;

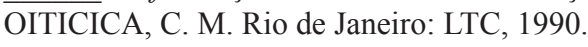

. A construção do real na criança. 3. ed. Tradução de: VASQUEZ, R. A. São Paulo: Ática, 1996.

PIAGET, J.; SZEMINSKA, A. A gênese do número na criança. 3. ed. Tradução de: OITICICA, C. M. Rio de Janeiro: Zahar, 1981.

RANGEL, A. C. S. Educação Matemática e a construção do número pela criança: uma experiência em diferentes contextos sócio-econômicos. Porto Alegre: Artes Médicas, 1992.

SOPHIAN, C. Le nombre et la gênese avant l'école primaire. Comment s'em inspirer pour enseigner les mathématiques. In : BIDEAU, J.; MELJAC, C.; FISHER, J. P. (Org.). Les chemins du nombre. Lille: Presses Universitaires de Lille, 1991. p. 35-58. 